Marquette University

e-Publications@Marquette

Biomedical Engineering Faculty Research and

Publications

Biomedical Engineering, Department of

$1-1-2011$

Effects of Wrist Tendon Vibration on Targeted Upper-Arm Movements in Poststroke Hemiparesis

Megan O. Conrad

Marquette University

Robert A. Scheidt

Marquette University, robert.scheidt@marquette.edu

Brian D. Schmit

Marquette University, brian.schmit@marquette.edu

Accepted version. Neurorehabilitation and Neural Repair, Vol. 25, No. 1 (January 2011): 61-70. DOI. (C) 2016 American Society of Neurorehabilitation. Used with permission. 


\title{
Effects of Wrist Tendon Vibration on Targeted Upper-Arm Movements in Poststroke Hemiparesis
}

\author{
Megan O. Conrad \\ Biomedical Engineering, Marquette University \\ Milwaukee, WI \\ Robert A. Scheidt \\ Biomedical Engineering, Marquette University \\ Milwaukee, WI \\ Brian D. Schmit \\ Biomedical Engineering, Marquette University \\ Milwaukee, WI
}

\begin{abstract}
:
Background. Impaired motor control of the upper extremity after stroke may be related to lost sensory, motor, and integrative functions of the brain. Artificial activation of sensory afferents might improve control of movement by adding excitatory drive to sensorimotor control structures. The authors evaluated the effect of wrist tendon vibration (TV) on paretic upper-arm stability during point-to-point planar movements. Methods. TV $(70 \mathrm{~Hz})$ was applied to the forearm wrist musculature of 10 hemiparetic stroke patients as they made center-out planar arm movements. End-point stability, muscle activity, and grip pressure were compared as patients stabilized at the target

Neurorehabilitation and Neural Repair, Vol 25, No. 1 (January 2011): pg. 61-70. DOI. This article is (C) SAGE Publications and permission has been granted for this version to appear in e-Publications@Marquette. SAGE Publications does not grant permission for this article to be further copied/distributed or hosted elsewhere without the express permission from SAGE Publications.
\end{abstract}


NOT THE PUBLISHED VERSION; this is the author's final, peer-reviewed manuscript. The published version may be accessed by following the link in the citation at the bottom of the page.

position for trials completed before, during, and after the application of the vibratory stimulus. Results. Prior to vibration, hand position fluctuated as participants attempted to maintain the hand at the target after movement termination. TV improved arm stability, as evidenced by decreased magnitude of hand tangential velocity at the target. Improved stability was accompanied by a decrease in muscle activity throughout the arm as well as a mean decrease in grip pressure. Conclusions. These results suggest that vibratory stimulation of the distal wrist musculature enhances stability of the proximal arm and can be studied further as a mode for improving end-point stability during reaching in hemiparetic patients.

Keywords: stroke rehabilitation, upper extremity, tendon vibration, reach, hemiparesis

\section{Introduction}

Disruption of sensory systems poststroke likely plays an important role in motor dysfunction of the hemiparetic arm. Sensory deficits, including the loss of proprioceptive and tactile sensation, are a common consequence of stroke ${ }^{1}$ and affect control of arm motion. For example, the absence of quality proprioceptive information could impair corrections to movement errors during reaching. Problems with motor planning could also be affected by disrupted spatial information of arm location. These problems in sensory systems poststroke affect the control of functional arm movements, ${ }^{2}$ including the ability to accurately translate and stabilize objects used in daily life.

Artificial sensory stimuli might improve the control of arm movements poststroke by providing an excitatory drive to sensorimotor control systems. Prolonged ( 2 hours) electrical stimulation applied to somatosensory nerves of the hand prior to functional hand testing improves hand performance. ${ }^{3}$ This effect carries over into motor training interventions such that somatosensory stimulation prior to training improves the rehabilitation effects of the training. ${ }^{4}$ The mechanisms underlying the therapeutic effects of somatosensory stimulation are unknown; although an important component likely involves increased strength, ${ }^{5}$ it is also possible that artificial sensory stimulation induces a persistent increase in the efficacy of descending cortical drive.

In contrast to previous studies, the current study applied tendon vibration (TV) to the forearm during planar point-to-point movements 
as a possible means of influencing control of the paretic arm (elbow and shoulder) posture and movement. TV is uniquely different from electric stimulation in that it primarily targets Ia-afferents ${ }^{6}$ providing selective excitation of proprioceptive input to the CNS. ${ }^{7}$ The ability to manipulate proprioceptive afferents is particularly desirable because disrupted planning and control of limb posture and movement is partially attributed to altered proprioception in chronic stroke. ${ }^{8}$ Applying TV to the forearm during arm movements provided a proprioceptive cue that was not directly related to movement kinematics in the designated motor task but nevertheless had the potential to influence activity within shoulder and elbow sensorimotor pathways.

We hypothesized that TV applied at the forearm would improve motor control of the hemiparetic arm. The hypothesis was tested using point-to-point movements in the horizontal plane with the paretic arm of stroke survivors. Analyses of kinematics, muscle activity, and grip pressure data were conducted to quantify changes in arm trajectory and end-point stability that occurred with application of the vibratory stimulus. The use of TV as a noninvasive, therapeutic intervention to improve motor function might have important ramifications in the rehabilitation of arm function poststroke.

\section{Materials and Methods}

\section{Participant Population}

A convenience sample of 10 chronic stroke survivors (age 45-63 years) participated in this study. All participants gave written informed consent, and all procedures were approved by the Marquette University Institutional Review Board and were in accordance with the Helsinki Declaration of 1975 . Inclusion criteria required that participants be at least 1 year poststroke and experience upperextremity hemiparesis; 6 participants experienced left-side hemiparesis, whereas the other 4 were affected on the right side. Exclusion criteria included inability to give informed consent, a diagnosis of any other neuromuscular disease, cognitive deficits, or the recent ( $<3$ months) use of botulinum toxin or other substances interfering with neuromuscular function. The participants were tested 
between 2 and 24 years poststroke and scored between 13 and 62 on the upper-extremity Fugl-Meyer test (maximum score 66). ${ }^{9} \mathrm{~A}$ neurologically intact control participant was tested for comparison of trajectory and muscle activity.

\section{Test Apparatus}

The study was conducted using a planar robot consisting of a 5bar linkage arm to constrain movement to the horizontal plane and provide measurements of end-point trajectory. Although most arm movements occur in 3D space, constraining movement to a single plane can simplify the complexity of motion while still allowing data analysis of multijoint movements. Previously, studies of planar arm movements have successfully characterized arm trajectories, ${ }^{10}$ evaluated impaired adaptation to force fields, ${ }^{8,11}$ and assessed changes in movement coordination during recovery ${ }^{12}$ of the hemiparetic arm.

While seated at the robot, a high-backed chair with chest straps provided support and prevented trunk movement. An overhead projector displayed experiment instructions, hand position, and target locations on a horizontal, opaque screen placed immediately above the plane of hand motion. The screen also obstructed the participant's view of the hand and forearm. The paretic arm was supported by a mobile armrest at all times, and a wrist brace was worn to ensure neutral wrist posture. A custom-made tendon vibrator consisting of an offset mass rotating about a motor shaft (Dr Fritz Faulhaber $\mathrm{GmbH} \&$ Co. KG, Schönaich, Germany) was affixed over the wrist flexor (WF) tendons. The wrist brace was attached to the robot handle, allowing the hand to grasp a bladder, which was used to measure grip pressure (Honeywell Sensotec, Columbus, Ohio) throughout the test period. A load cell (JR3 Inc, Woodland, California) was mounted below the robot handle for measuring hand forces $\left(F_{x}, F_{y}, F_{z}\right)$. The robot arm was instrumented with 17-bit optical encoders (Gurley Instruments Inc, Troy, New York) allowing hand position calculations to within $0.04 \mathrm{~mm}$.

Surface electromyograms (EMGs) were recorded from WF (flexor carpi radialis), wrist extensor (WE; extensor carpi ulnaris), brachioradialis (BRD), biceps (BI), lateral head of the triceps (TRI), anterior deltoid (AD), and posterior deltoid (PD) of the paretic arm. The skin over each muscle belly was cleaned and lightly abraded 
NOT THE PUBLISHED VERSION; this is the author's final, peer-reviewed manuscript. The published version may be accessed by following the link in the citation at the bottom of the page.

before attaching disposable $\mathrm{Ag} / \mathrm{AgCl}$ electrodes (Vermed Inc, Bellows Falls, Vermont). EMG signals were amplified $(\times 1000)$ and band-pass filtered (10-1000 Hz; Bortec Biomedical Ltd, Calgary, AB, Canada) prior to sampling.

\section{Experimental Protocol}

Prior to experimental testing, a licensed physical therapist conducted the upper-extremity portion of the Fugl-Meyer Assessment of Physical Performance ${ }^{9}$ and took goniometric measurements of passive and active joint range of motion at the shoulder, elbow, and wrist. EMG data were recorded during maximum voluntary contractions (MVCs) targeting wrist flexion and extension, elbow flexion and extension, and shoulder flexion and extension. Each MVC was taken with the arm supported in the armrest, the wrist in a neutral position, and the elbow bent to $90^{\circ}$ flexion. Two MVC trials were completed for each targeted torque. During each trial, the participant was instructed to make the desired motion (eg, wrist flexion) exerting as much force as possible for $4 \mathrm{~s}$. These recorded EMG data were later used to normalize EMG data across participants. Note that normalizing EMG to MVC can be problematic in those with paresis because of some individuals' inability to maximally excite muscle activity. However, an initial analysis of the EMG data indicated a bias toward those with higher functional ability. Therefore, we chose to normalize to MVC as a conservative measure of the observed response.

Participants were given visual feedback of their actual hand position by a red cursor $(r=0.25 \mathrm{~cm})$ that was projected onto the screen. A white circle $(r=0.5 \mathrm{~cm})$ was also projected onto the screen at the center of the participant's workspace, marking home position. Each trial consisted of 1 of 8 possible targets $(r=0.25 \mathrm{~cm})$ appearing on the screen. The targets were equally spaced around a circle $(r=14$ $\mathrm{cm}$ ) centered on the home position. Targets were positioned within the passive range of motion for hemiparetic participants, and each required varying levels of elbow and shoulder movement. At the beginning of each trial, the robot moved the participant's hand to home position and held it there for $1 \mathrm{~s}$ before smoothly disengaging the motors. Participants were then instructed to move as quickly as

Neurorehabilitation and Neural Repair, Vol 25, No. 1 (January 2011): pg. 61-70. DOI. This article is (C SAGE Publications and permission has been granted for this version to appear in e-Publications@Marquette. SAGE Publications does not grant permission for this article to be further copied/distributed or hosted elsewhere without the express permission from SAGE Publications. 
possible from home position to the target when it appeared and to hold the red cursor inside the target circle until the target was removed ( $4 \mathrm{~s}$ after initiation of movement). For all trials, there was a $1: 1$ relationship between the home and target position projected on the screen and the actual required movement distance of the hand. The order of target directions was randomized. Participants were allowed to practice sets of 8 arm movements until they were comfortable with the task, to reduce learning effects. After 80 baseline trials (pre-TV), 70-Hz TV was applied to forearm flexor tendons throughout the next 40 trials (TV). During the 40 TV trials, TV was turned on $1 \mathrm{~s}$ prior to the target appearing and was removed at the same time the target disappeared (approximately $5 \mathrm{~s}$ duration per trial). Therefore, the vibration remained on for the duration of movement and hold period at the target but was turned off between trials. The participant then completed 80 trials without TV to measure any aftereffects (post-TV). Hand position, velocity, and grip force data were compared between the 3 test conditions (pre-TV, TV, and postTV).

A total of 5 participants returned for a second visit, repeating the entire experiment without TV. The second session was conducted a minimum of 3 weeks following the initial TV session. Data from the second visit were used to verify that effects were because of TV and not learning or fatigue.

\section{Data Analysis}

Tangential velocity was calculated from the $x$ and $y$ position data obtained from the optical encoders. The tangential velocity profiles were used to identify start time $\left(t_{\mathrm{s}}\right)$ and end time $\left(t_{\mathrm{e}}\right)$ of each movement. The $t_{\mathrm{s}}$ was identified as the threshold at which the hand surpassed $20 \%$ of its maximum tangential velocity, whereas the $t_{\mathrm{e}}$ occurred when the hand returned below $20 \%$ of that peak velocity. Identification of $t_{\mathrm{s}}$ and $t_{\mathrm{e}}$ were used to separate data from each trial into 2 periods: (1) initial movement (the window of time between $t_{\mathrm{s}}$ and $t_{\mathrm{e}}$ ) and (2) hold (a 1-s window following $t_{\mathrm{e}}$ ). Instability was visibly apparent during the hold period. The power spectral density of the tangential velocity was used to evaluate the magnitude of hand position fluctuations around the target during the hold period. The 
area under the power spectral density between 1 and $5 \mathrm{~Hz}$ was calculated to identify the stability error $\left(S_{e}\right)$ in hand position.

Muscle activity was monitored throughout each trial via surface electrodes. All EMG data were forward and backward filtered using second-order Butterworth filters. The data were band-pass filtered (10-350 Hz) and notch filtered for line noise $(59-61 \mathrm{~Hz})$ and to remove noise resulting from the vibratory stimulus (68-72 Hz and $136-144$ $\mathrm{Hz}$ ). The root-mean square (RMS) of all filtered EMG data was calculated using a $100-\mathrm{ms}$ sliding window. For normalization across participants, the peak RMS value for each muscle group was obtained from the maximum data point taken from a 1-s window of time from the appropriate MVC trial. All EMG data were divided by the peak RMS value from the MVC trials to obtain a percentage of the maximum voluntary EMG. The EMG area, or area under the normalized RMS curve, was calculated by integrating the RMS curve over the 1 -s hold period for each trial.

Grip pressure data were low-pass filtered at $5 \mathrm{~Hz}$ using a second-order Butterworth filter. The relative increase in grip pressure was calculated to be the difference between the initial grip pressure and peak grip pressure occurring in each trial.

Individual multiple-factor ANOVAs identified the effect of TV on stability error, EMG amplitudes, and grip pressure. Tukey post hoc tests were used for pairwise comparisons between blocks pre-TV, TV, and post-TV. Pearson correlation analyses were used to evaluate the relationship between Fugl-Meyer scores, stability error, and peak movement velocity. Statistical tests were conducted at a family error rate of $a=.05$.

\section{Results}

\section{Movement Kinematics}

Compared with goal-directed arm movements made by healthy controls, movements made by the stroke survivors typically fell short of the target position. Whereas a healthy individual experienced no difficulty reaching the target position, the mean ( \pm SD [standard 
deviation]) absolute distance between hand position and target location at the end of a trial for stroke patients was $3.6 \pm 1.2 \mathrm{~cm}$. For stroke participants, stabilization at the target was characterized by corrective movements, presumably because of difficulty stopping the arm at the desired location. The hand position often fluctuated during the hold portion of the movement, as evidenced in plots of both tangential velocity and trajectory (Figure 1 ). In addition, stroke survivors generally had more success at making medial/lateral (average final distance from target recorded at T1 and T5 $=2.4 \pm 0.6$ $\mathrm{cm}$ ) than proximal/distal movements (average final distance from target at T3 and T7 $=4.9 \pm 0.5 \mathrm{~cm}$ ). Those with higher Fugl-Meyer scores experienced a greater range of motion but also displayed greater instability at the hold position (Figure 2).

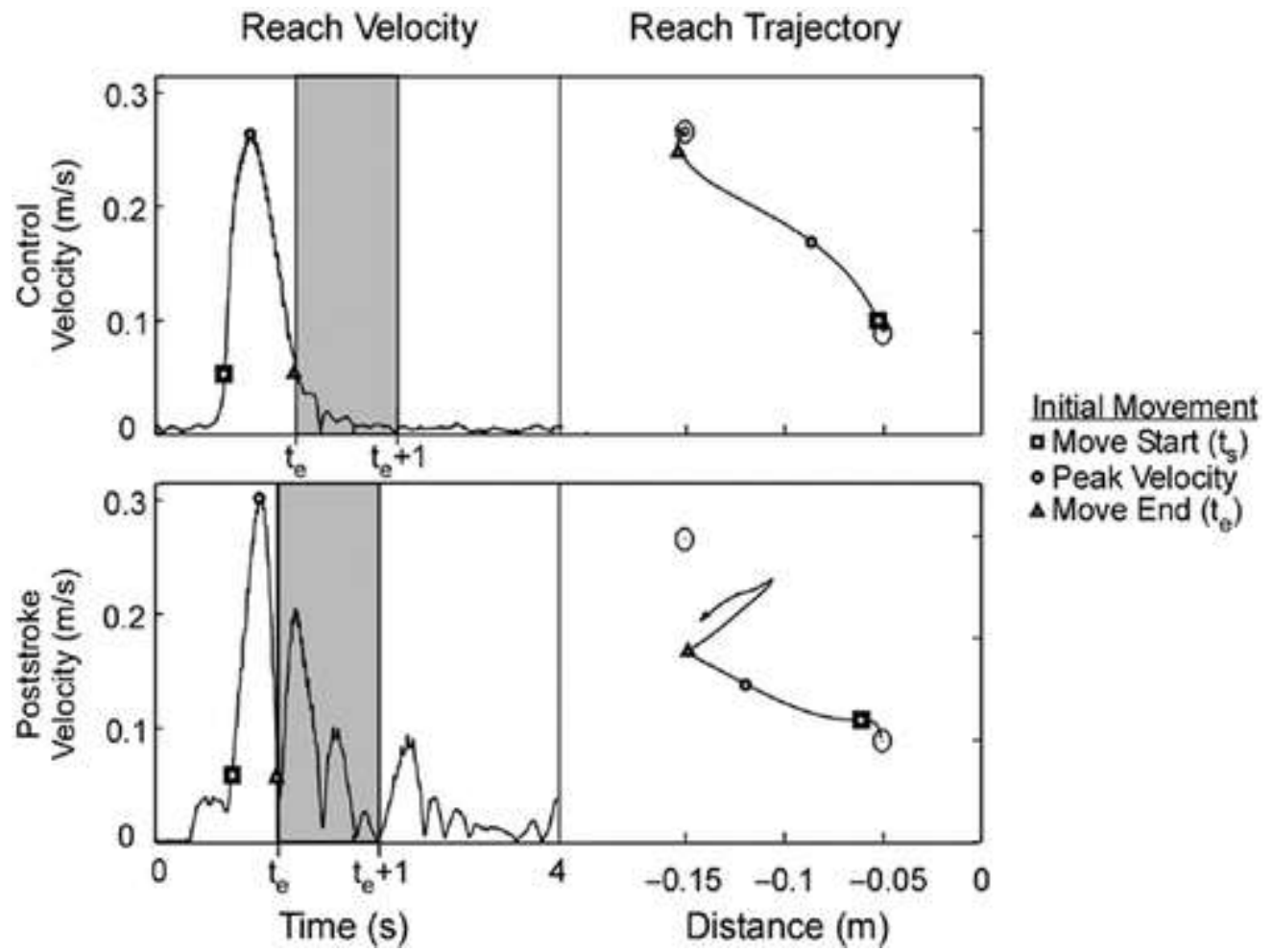

Figure 1. Movement characteristics: a sample movement trial completed by a neurologically intact individual results in smooth movement trajectories and bellshaped velocity profiles. Comparatively, movement trajectories made by chronic stroke patients had a tendency to fall short of the target. Stroke patients also experienced greater instability at the end of each trial as indicated by changes in movement direction and oscillations in velocity following the initial arm movement. The shaded region represents the 1-s period of instability that was evaluated in this experiment. 
A

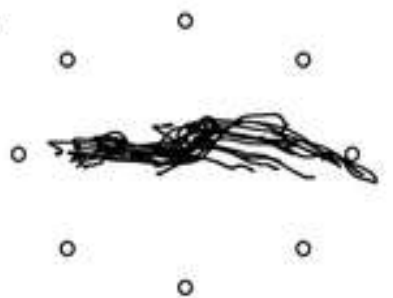

Fugl-Meyer $=11$

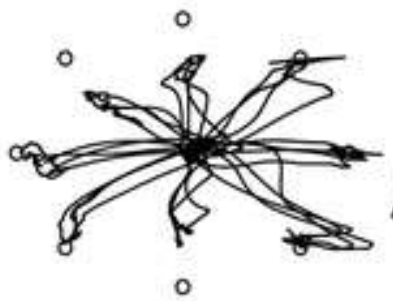

Fugl-Meyer $=30$

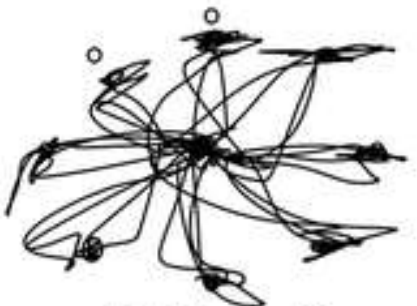

Fugl-Meyer $=55$

B

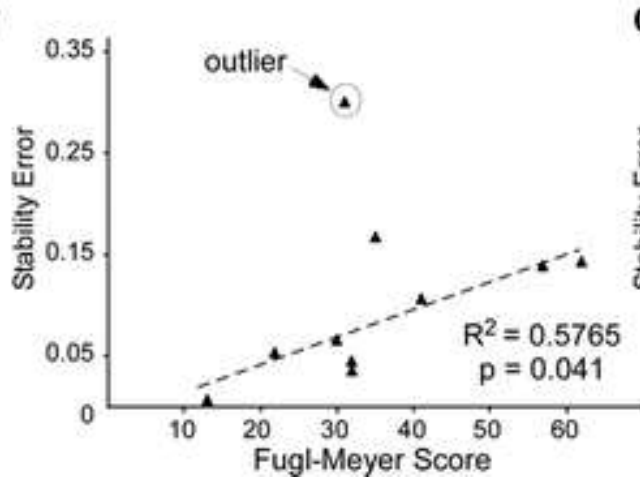

C

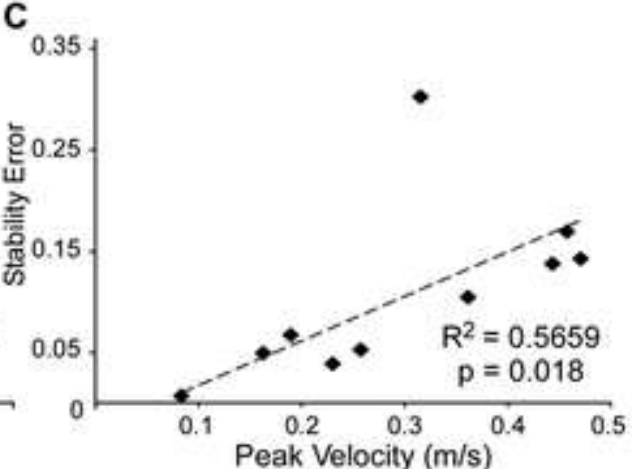

Figure 2. Correlations with Fugl-Meyer Scores: stroke survivors with high upperextremity Fugl-Meyer scores experienced larger range of motion but had greater instability at the target position (A). Stability error positively correlated with FuglMeyer scores (B) and with peak movement velocity (C).

\section{Arm Stability}

When averaged across all pre-TV trials, correlations of stability error with Fugl-Meyer scores indicated that those with high functional ability experienced higher stability error, or greater instability (Figure 2B). Additionally, stability error positively correlated with the peak movement velocity (Figure 2C).

Applying TV to the WF tendons affected hand stability at the end of each movement. A decrease in mean stability error $\left(S_{e}\right.$, mean $\left.\pm S D\right)$ was observed with TV at 5 of the 8 target positions (T1, T2, T3, T4, and T8), although the effect was not significant when averaged across all targets $\left(S_{\mathrm{e}, \text { Pre }}=0.133 \pm 0.048, S_{\mathrm{e}, \mathrm{TV}}=0.096 \pm 0.029 ; P>.05\right)$. Post-TV, $S_{\mathrm{e}}$ remained significantly lower than during pre-TV trials $\left(S_{\mathrm{e}, \text { Post }}=0.077 \pm 0.025 ; P<.01\right)$. The $S_{\mathrm{e}}$ at each individual target position is depicted in Figure 3. Note that in pre-TV trials, the 3 targets not exhibiting decreases in stability with TV had relatively low initial $S_{\mathrm{e}}$ compared with the other targets. The ANOVA indicated no significant 
difference between the $S_{\mathrm{e}}$ recorded during TV and post-TV trials ( $P$ $>$.05).

\section{Stability Error}
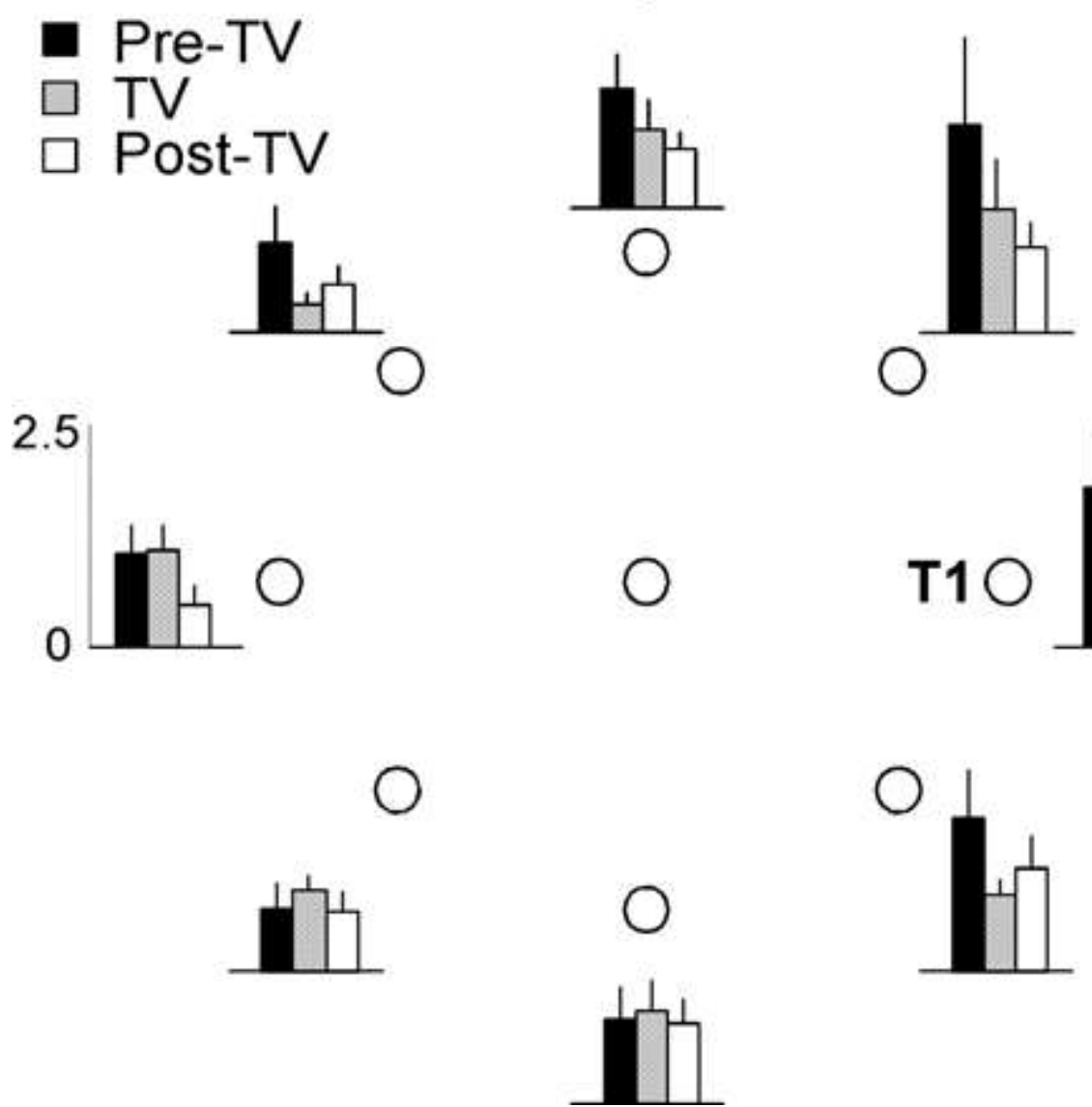

Figure 3. Stability error: mean stability error $( \pm S D)$ decreased in the postvibration trials at T1 to T5 and T8 (ANOVA, $P<.01$ ).

Abbreviations: TV, tendon vibration; SD, standard deviation.

Data from the 5 participants who returned for a second visit indicated that there was no significant change in performance between the 3 blocks of trials when TV was not administered in the middle block $\left(S_{e, \text { Pre }}=0.128 \pm 0.011, S_{e, \text { No-TV }}=0.133 \pm 0.014, S_{e, \text { Post }}=0.132\right.$ $\pm 0.014 ; P=.514)$.

\section{Muscle Activity}

During the 1-s hold period following $t_{\mathrm{e}}$, TV caused a marked decrease in EMG area for 6 of the 7 muscle groups (WF, WE, BRD, BI, $A D, P D ; P<.05)$ as illustrated in Figure 4. For the TRI, decreased

Neurorehabilitation and Neural Repair, Vol 25, No. 1 (January 2011): pg. 61-70. DOI. This article is (C) SAGE Publications and permission has been granted for this version to appear in e-Publications@Marquette. SAGE Publications does not grant permission for this article to be further copied/distributed or hosted elsewhere without the express permission from SAGE Publications. 
muscle activity was observed but was not significant $(P=.051)$. EMG area remained low $(P<.01)$ during the post-TV trials compared with pre-TV in all muscles other than the TRI. Note that although the participants' arms were placed in an armrest, resting muscle activity (prior to initiating movement) ranged from $1 \%$ to $60 \%$ MVC for stroke patients.
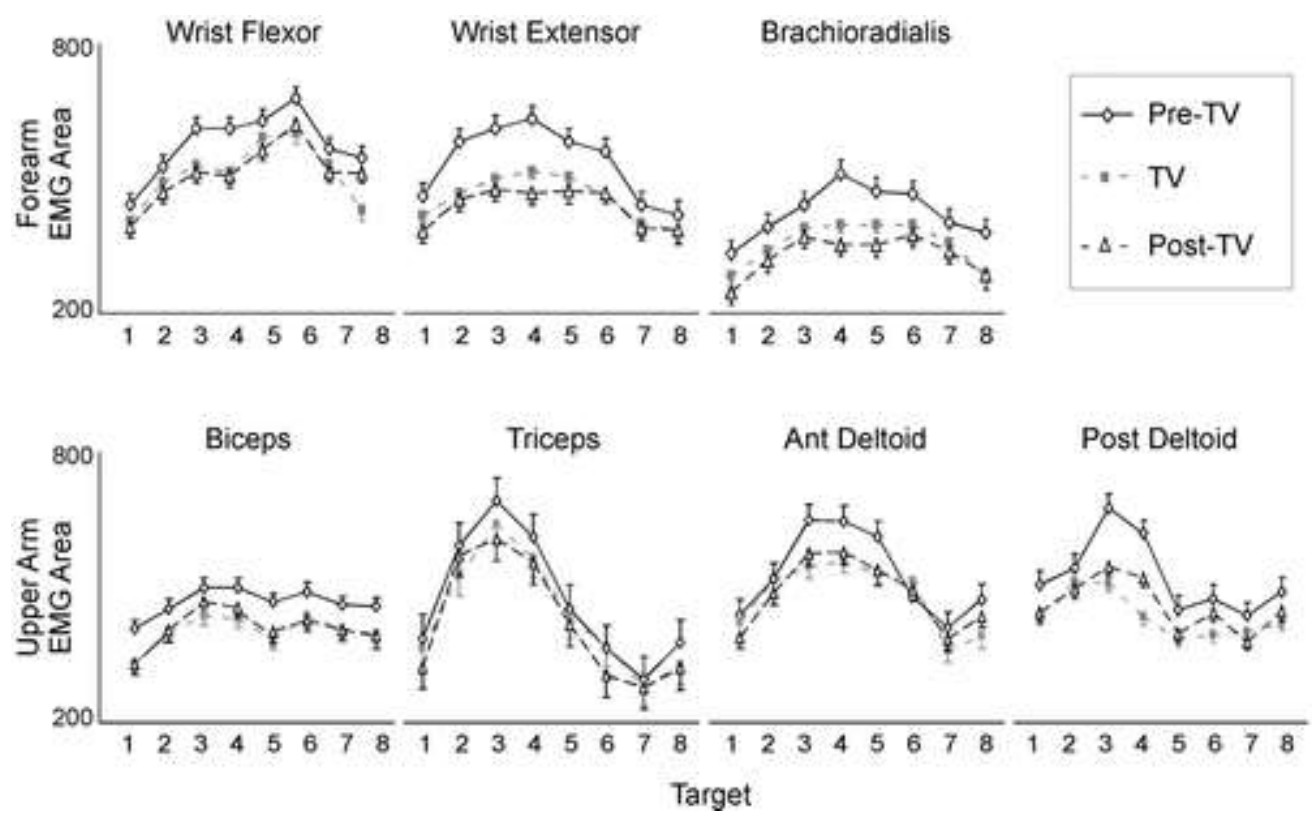

Figure 4. EMG response to TV: during stabilization, vibration elicited a significant decrease in arm muscle activity (mean $\pm \mathrm{SD}$ ) for the wrist flexor, wrist extensor, brachioradialis, biceps, anterior deltoid, and posterior deltoid muscle groups (ANOVA, $P<.05$ ) but did not significantly decrease in the triceps (ANOVA, $P=.051$ ). Activity remained low postvibration in all muscles except the triceps (ANOVA, $P<.05$ ). Abbreviations: EMG, electromyogram; TV, tendon vibration; SD, standard deviation.

\section{Grip Pressure}

Throughout each trial, stroke participants had a tendency to tighten their grip, causing peak grip pressure to occur toward the end of the movement and to remain elevated while holding at the target location. TV elicited relaxation in grip pressure during the latter half of each trial (Figure 5). The mean peak grip pressure significantly decreased from $39.1 \pm 13.3 \mathrm{kPa}$ to $33.5 \pm 11.3 \mathrm{kPa} ; P<.001)$ during TV and remained significantly lower $(32.6 \pm 10.4 \mathrm{kPa} ; P<.001)$ throughout post-TV trials.

Neurorehabilitation and Neural Repair, Vol 25, No. 1 (January 2011): pg. 61-70. DOI. This article is C SAGE Publications and permission has been granted for this version to appear in e-Publications@Marquette. SAGE Publications does not grant permission for this article to be further copied/distributed or hosted elsewhere without the express permission from SAGE Publications. 
A

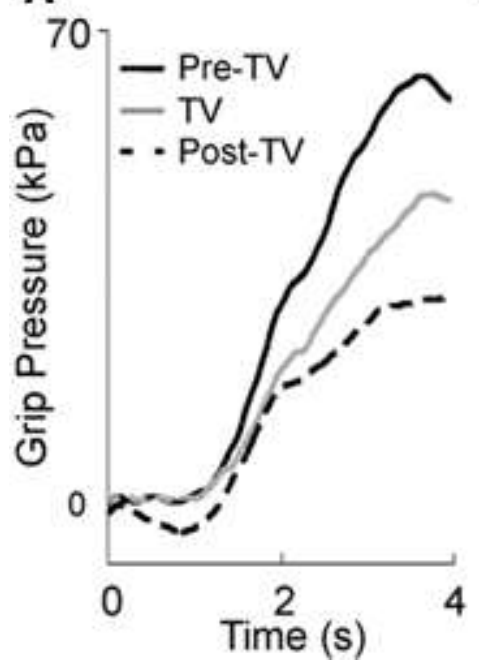

B

45

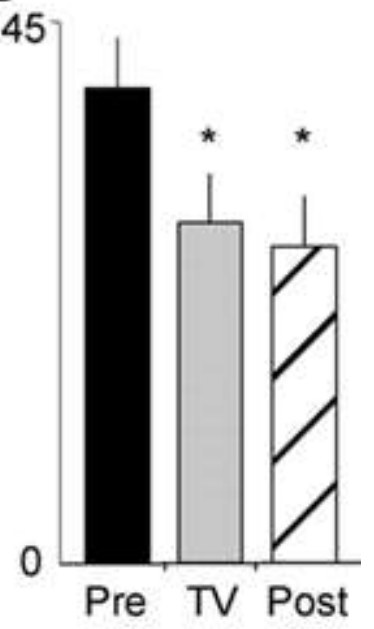

Figure 5. Grip pressure: A. Mean grip pressure (averaged across all trials within each block for a single participant) increased throughout each trial and peaked while holding at the target position. B. Significant decreases in peak grip pressure (mean \pm SD) were observed during previbration and postvibration (ANOVA, $P<.001$ ). Abbreviations: TV, tendon vibration; SD, standard deviation.

\section{Discussion}

This study demonstrated that activation of wrist proprioceptors through TV improved stability of the entire hemiparetic arm after goaldirected arm movements. Specifically, at the end of a targeted arm movement, a decrease in stability error was observed at the end point. Because of the nature of planar arm movement and the fact that the wrist was immobilized, changes in stability can be attributed to improved control at the elbow and shoulder joint. Functionally, these results were associated with decreased fluctuations in hand movements when stroke patients attempted to stabilize their hand after a point-to-point arm movement. Improved stabilization was associated with decreases in overall muscle activity throughout the arm, suggesting an improved ability to modulate motor drive or associated reflexes. The peak grip pressure recorded in the hand also decreased, supporting the notion of an improved ability to generate targeted muscle activity throughout the arm.

Fluctuations in movement trajectories at the end point were consistent with movement about the shoulder joint. The direction of the oscillatory movement about the target appeared to correspond with movement related to shoulder joint variability and was 
perpendicular to the outstretched arm (ie, favoring the medial-lateral direction). These oscillations may have been caused by rapid correctional movements in response to inaccurate initial directions and a failure to stop the arm at the desired limb location. Weakness and the stroke survivor's inability to rapidly generate muscle force may also contribute to overshooting the target. ${ }^{13}$ Because the shoulder appeared to have greater mobility than the elbow, fluctuations in shoulder angle could reflect a dominant shoulder strategy in arm movements or an increased stiffness of the elbow.

\section{Possible Mechanisms for Improved Arm Stability}

A primary finding in this study was that improved stability associated with TV of the forearm flexor muscles was accompanied by decreased activity in muscles throughout the arm, evidenced by decreases in EMG and grip pressure. The high levels of EMG activity observed in both the move and hold portions of the initial pre-TV trials in this experiment are consistent with heightened reflex activity. In healthy individuals, the motor cortex modulates spinal reflexes via brainstem pathways and by direct corticospinal input to the Ia inhibitory interneurons. ${ }^{14}$ In this manner, the cortex can utilize reflex activity to simplify programming of complex movements. However, for chronic stroke survivors, the disruption of cortical activity and associated corticospinal drive is often associated with a disinhibition of reflex activity, which contributes to spasticity. ${ }^{15,16}$ Stroke typically results in a heightened stretch reflex excitability at the elbow, ${ }^{15}$ produced in part by a decrease in stretch reflex set point ${ }^{17}$ or threshold. ${ }^{18,19}$ It has been proposed that this decrease in threshold of both elbow flexors and extensors could result in threshold overlap, ${ }^{20}$ effectively producing coactivation at the elbow during volitional movements. In the current study, improved arm stabilization occurred with a decrease in muscle activity throughout the arm in both flexors and extensors, which could reflect a normalization of reflex control.

The decrease in EMG of elbow and shoulder muscles with TV during a simultaneous increase in end-point stability indicates that cocontraction, a strategy commonly utilized by the intact nervous system to increase joint impedance, ${ }^{21,22}$ which helps maintain arm stability, ${ }^{23}$ was actually decreased at the end of the movement in our patient 
group during and following vibratory stimulation. This suggests that spastic coactivation, typically observed in stroke survivors does not increase the stability of the arm with vibration. Instead, accuracy is improved in these participants through a mechanism that acts to terminate movement accurately at the target. Because stretch reflexes have also been implicated in stiffness regulation ${ }^{24}$ and can play an important role in stabilizing the limb at the end of movement, it is possible that the improvements in stability associated with TV of the forearm observed here are a result of improved regulation of reflex excitability. An increase in reflex threshold might decrease cocontraction while normalizing reflex excitability during end-point stabilization.

Another explanation for the observed effects of TV on arm stabilization at the end of movement could be improved cortical control of the movement. Augmenting sensory input to the CNS increases activity in both the sensory and motor cortices. ${ }^{3,25}$ Facilitation of motor cortical activity could improve the fidelity of initial motor commands (ie, feed-forward control). Alternately, improvements in descending cortical control may act to improve the modulation of spinal reflex systems, at least in some movement directions, thereby normalizing stiffness regulation of the arm.

A potential role of cortical structures in vibration-induced improvements in arm stability is indirectly supported by observations of increased cortical excitation associated with TV. In the periphery, TV entrains muscle spindle Ia-afferent firing rates at a one-to-one ratio up to $80 \mathrm{~Hz},{ }^{6}$ thereby, augmenting proprioceptive input to the CNS. ${ }^{7}$ Imaging studies indicate that stimulation-related activity in response to $70-$ to $80-\mathrm{Hz}$ TV occurs not only in the somatosensory cortex but also in the motor cortex, premotor cortex, and supplementary and cingulate motor areas. ${ }^{25-27}$ Strong excitatory neuronal projections exist between area $3 a$ and the motor cortex, at least in the cat. ${ }^{28}$ Therefore, it is not unreasonable to suggest that excitation of these motor areas might also occur in people through direct neuronal projections from area $3 a$ of the somatosensory cortex, driven directly by Ia afferents. ${ }^{29}$ Indeed, motor-evoked potential amplitudes in arm musculature are augmented by TV as early as $0.5 \mathrm{~s}$ after the onset of TV, ${ }^{30}$ a response that is attributed to increased cortical activation. ${ }^{31}$ The optimum frequency to evoke the response lies near $75 \mathrm{~Hz}{ }^{32}$ the vibratory and permission has been granted for this version to appear in e-Publications@Marquette. SAGE Publications does not grant permission for this article to be further copied/distributed or hosted elsewhere without the express permission from SAGE Publications. 
frequency with the strongest activation of Ia muscle afferents. ${ }^{6}$ Furthermore, MEP augmentation caused by 15 minutes of cyclic vibration (30 s on/15 s off) remains high up to 5 minutes after removal of the vibratory stimulus. ${ }^{33}$ Taken together, these studies support the idea that TV, through enhanced afferent feedback, has the ability to increase cortical activation and corticomotor drive both during and immediately after TV. Drive to these pathways might provide the improved arm stability observed in this study.

\section{Quality of Movement for Participants With Varying Functional Ability}

An interesting observation of this study was the differences in arm trajectories across participants. Specifically, notable differences in the quality of arm movement existed when comparing participants with varying Fugl-Meyer scores. Those with high Fugl-Meyer scores experienced better range of motion but also greater instability at the end of point-to-point movements.

Although it was not the primary objective of this study, we observed that many participants, particularly those with low FuglMeyer scores $(<25)$, were more effective at medial-lateral movements than at moving in the proximal/distal direction (Figure 2A). For this experiment, proximal/distal movements required significant elbow flexion and extension, whereas medial-lateral targets could be obtained primarily through shoulder motion. The relative sparing of motor control in proximal joints in chronic hemiparesis ${ }^{34}$ may contribute to our observation of better range of motion in the mediallateral plane (Figure 2A). In contrast, recent research has disputed the idea that active range of motion is spared at proximal joints in stroke, suggesting that greater deficits in the hand and wrist are a result of decreased position control throughout the arm, not just at distal joints. ${ }^{35,36}$ Our results suggest unique motor control deficits for the elbow (loss of active range) and shoulder (instability).

Perhaps a less intuitive finding of this study was that those with high Fugl-Meyer scores also experienced the greatest instability at the end of a movement (Figure 2B). In this experiment, participants were instructed to move as fast as possible from the home position to the 
target. As a result, those with high Fugl-Meyer scores were capable of making faster arm movements and, on average, had larger mean velocities across all trials. Further analysis of the data showed a positive correlation between stability error and peak velocity during movement (Figure $2 \mathrm{C}$ ). This is an important observation because most movement during daily life occurs at self-selected movement velocities. These results suggest that individuals who have experienced significant recovery may still experience instability during activities of daily living and benefit from therapeutic interventions.

\section{Clinical Applications}

Historically, the use of sensory interventions to treat CNS disorders has had both clinical and research precedents. The Rood approach to physical therapy, dating to the 1950s, advocated the application of sensory stimuli (such as touch, temperature, and pressure) to either facilitate or inhibit movement. ${ }^{37}$ More recently, electric stimulation has been investigated as a nonspecific sensory stimulus to improve performance on functional hand tests for patients with cortical and subcortical lesions. ${ }^{3-5,38}$ The mechanisms behind improved functional performance might stem from augmented corticomotoneuronal excitability caused by enhanced cortical facilitation and reduced intracortical inhibition. ${ }^{39,40}$ The effects of TV on arm stability at the end of a point-to-point movement may reflect the same mechanism and may also have important implications in rehabilitation poststroke.

Despite an expanding interest in sensory interventions, ${ }^{41,42}$ there have been a limited number of studies exploring the therapeutic use of TV. A recent study, aimed at using TV to train sensorimotor connectivity in the brain, demonstrated improved motor function at the wrist and ankle. ${ }^{43}$ Regarding the effects of TV across multiple joints, only a single reported case study has been published citing improved shoulder flexion with vibratory stimulus to the hand musculature in an acute stroke patient. ${ }^{44}$ The present study is important because it demonstrates that TV improves stability throughout the hemiparetic arm by providing sensory feedback to the CNS. Additionally, this study finds that TV can be applied concurrently with a set of arm movements, eliciting changes in motor control both 
during those tasks and in subsequent movements. This contrasts with prior studies that primarily focus on applying the sensory intervention prior to testing motor performance. Future studies are needed to clarify whether the effects of TV translate beyond a single session. Additionally, experiments conducted in 3D space or with activities of daily living could further the ability to successfully apply this sensory intervention in a clinical setting.

\section{Acknowledgements}

We thank Allison Hyngstrom, PT, PhD, and Andrew Starsky, PT, $\mathrm{PhD}$, for their assistance in completing the clinical assessments of the participants in this study.

The author(s) declared no potential conflicts of interest with respect to the authorship and/or publication of this article.

The author(s) disclosed receipt of the following financial support for the research and/or authorship of this article: this work was funded through NIH Research Grant \# R01-NS052509.

\section{References}

1 Carey LM, Matyas TA, Oke LE. Sensory loss in stroke patients: effective training of tactile and proprioceptive discrimination. Arch Phys Med Rehabil. 1993;74:602-611.

2 Tyson SF, Hanley M, Chillala J, Selley AB, Tallis RC. Sensory loss in hospital-admitted people with stroke: characteristics, associated factors, and relationship with function. Neurorehabil Neural Repair. 2008;22:166-172.

3 Wu CW, Seo H, Cohen LG. Influence of electric somatosensory stimulation on paretic-hand function in chronic stroke. Arch Phys Med Rehabil. 2006;87:351-357.

4 Celnik P, Hummel F, Harris-Love M, Wolk R, Cohen LG. Somatosensory stimulation enhances the effects of training functional hand tasks in patients with chronic stroke. Arch Phys Med Rehabil. 2007;88:1369-1376.

5 Conforto $A B$, Kaelin-Lang A, Cohen LG. Increase in hand muscle strength of stroke patients after somatosensory stimulation. Ann Neurol. $2002 ; 51: 122-125$.

Neurorehabilitation and Neural Repair, Vol 25, No. 1 (January 2011): pg. 61-70. DOI. This article is (C SAGE Publications and permission has been granted for this version to appear in e-Publications@Marquette. SAGE Publications does not grant permission for this article to be further copied/distributed or hosted elsewhere without the express permission from SAGE Publications. 
$6 \quad$ Roll JP, Vedel JP, Ribot E. Alteration of proprioceptive messages induced by tendon vibration in man: a microneurographic study. Exp Brain Res. $1989 ; 76: 213-222$.

7 Cordo P, Gurfinkel VS, Bevan L, Kerr GK. Proprioceptive consequences of tendon vibration during movement. J Neurophysiol. $1995 ; 74: 1675-1688$.

8 Scheidt RA, Stoeckman T. Reach adaptation and final position control amid environmental uncertainty after stroke. J Neurophysiol. 2007; 97:2824-2836.

9 Gladstone DJ, Danells C, Black SE. The Fugl-Meyer assessment of motor recovery after stroke. Neurorehabil Neural Repair. 2002;16:232240.

Beer RF, Dewald JPA, Rymer WZ. Deficits in the coordination of multijoint arm movements in patients with hemiparesis: evidence for disturbed control of limb dynamics. Exp Brain Res. 2000;131:305319.

Takahashi CD, Reinkensmeyer DJ. Hemiparetic stroke impairs anticipatory control of arm movement. Exp Brain Res. 2003;149:131-140.

Rohrer B, Fasoli S, Krebs HI, . Movement smoothness changes during stroke recovery. J Neurosci. 2002;22:8297-8304.

Canning CG, Ada L, O'Dwyer N. Slowness to develop force contributes to weakness after stroke. Arch Phys Med Rehabil. 1999;80:66-70.

Iles JF, Pisini JV. Cortical modulation of transmission in spinal reflex pathways of man. J Physiol. 1992;455:425-446.

Rymer WZ, Katz RT. Spastic hypertonia: mechanisms and measurement. Phys Med Rehabil. 1989;70:144-155.

Elbasiouny SM, Moroz D, Bakr MM, Mushahwar VK. Management of spasticity after spinal cord injury: current techniques and future directions. Neurorehabil Neural Repair. 2010;24:23-33.

Schmit BD, Dhaher Y, Dewald JPA, Rymer WZ. Reflex torque responses to constant velocity movements in spastic elbow muscles: theoretical analyses and implications for quantification of spasticity. Ann Biomed Eng. 1999;27:815-829.

Powers RK, Marder-Meyer J, Rymer WZ. Quantitative relations between hypertonia and stretch reflex threshold in spastic hemiparesis. Ann Neurol. 1988;23:115-124.

Levin MF, Feldman AG. The role of stretch reflex threshold regulation in normal and impaired motor control. Brain Res. 1994;657:23-30.

Neurorehabilitation and Neural Repair, Vol 25, No. 1 (January 2011): pg. 61-70. DOI. This article is (C SAGE Publications and permission has been granted for this version to appear in e-Publications@Marquette. SAGE Publications does not grant permission for this article to be further copied/distributed or hosted elsewhere without the express permission from SAGE Publications. 
Musampa NK, Mathieu PA, Levin MF. Relationship between stretch reflex thresholds and voluntary arm muscle activation in patients with spasticity. Exp Brain Res. 2007;181:579-593.

Osu R, Burdet E, Franklin DW, Milner T, Kawato M. Different mechanisms involved in adaptation to stable and unstable dynamics. J Neurophysiol. 2003;90:3255-3269.

Hogan N. Adaptive control of mechanical impedance by coactivation of antagonist muscles. IEEE Trans Automat Contr. 1984;29:681-690.

Milner TE. Adaptation to destabilizing dynamics by means of muscle cocontraction. Exp Brain Res. 2002;143:406-416.

Crago PE, Houk JC, Hasan Z. Regulatory actions of human stretch reflex. J Neurophysiol. 1976;39:925-935.

Romaiguere $\mathrm{P}$, Anton JL, Roth M, Casini L, Roll JP. Motor and parietal cortical areas both underlie kinaesthesia. Cogn Brain Res. 2003; $16: 74-82$.

Naito E, Ehrsson HH, Geyer S, Zilles K, Roland PE. Illusory arm movements activate cortical motor areas: a positron emission tomography study. J Neurosci. 1999;19:6134-6144.

Radovanovic S, Korotkov A, Ljubisavljevic M, . Comparison of brain activity during different types of proprioceptive inputs: a positron emission tomography study. Exp Brain Res. 2002;143:276-285.

Zarzecki P, Shinoda Y, Asanuma H. Projections from area $3 a$ to the motor cortex by neurons activated from group i muscle afferents. Exp Brain Res. 1978;33:269-282.

Huerta MF, Pons TP. Primary motor cortex receives input from area $3 a$ in macaques. Brain Res. 1990;537:367-371.

Siggelkow S, Kossev A, Schubert M, Kappels H, Wolf W, Dengler R. Modulation of motor evoked potentials by muscle vibration: the role of vibration frequency. Muscle Nerve. 1999;22:1544-1548.

Kossev A, Siggelkow S, Schubert M, Wohlfarth K, Dengler R. Muscle vibration: different effects on transcranial magnetic and electrical stimulation. Muscle Nerve. 1999;22:946-948.

Steyvers M, Levin O, Verschueren SMP, Swinnen SP. Frequencydependent effects of muscle tendon vibration on corticospinal excitability: a TMS study. Exp Brain Res. 2003;151:9-14.

Smith L, Brouwer B. Effectiveness of muscle vibration in modulating corticospinal frequency. J Rehabil Res Dev. 2005;42:787-794.

Colebatch J, Gandevia S. The distribution of muscular weakness in upper motor neuron lesions affecting the arm. Brain. 1989;112:749-763.

Neurorehabilitation and Neural Repair, Vol 25, No. 1 (January 2011): pg. 61-70. DOI. This article is (C SAGE Publications and permission has been granted for this version to appear in e-Publications@Marquette. SAGE Publications does not grant permission for this article to be further copied/distributed or hosted elsewhere without the express permission from SAGE Publications. 
NOT THE PUBLISHED VERSION; this is the author's final, peer-reviewed manuscript. The published version may be accessed by following the link in the citation at the bottom of the page.

35

Lang CE, Beebe JA. Relating movement control at 9 upper extremity segments to loss of hand function in people with chronic hemiparesis. Neurorehabil Neural Repair. 2007;21:279-291.

Beebe JA, Lang CE. Absence of a proximal to distal gradient of motor deficits in the upper extremity early after stroke. Clin Neurophysiol. 2008;19:2074-2085.

Rood MS. Neurophysiologic reaction as a basis for physical therapy. Phys Ther Rev. 1954;34:444-449.

Cuypers K, Levin O, Thijs H, Swinnen SP, Meesen RL. Long-term TENS treatment improves tactile sensitivity in MS patients. Neurorehabil Neural Repair. 2010;24:420-427

Ridding MC, Brouwer B, Miles TS, Pitcher JB, Thompson PD. Changes in muscle responses to stimulation of the motor cortex induced by peripheral nerve stimulation in human subjects. Exp Brain Res. 2000;131:135-143.

Kaelin-Lang A, Luft AR, Sawaki L, Burstein AH, Sohn YH, Cohen LG. Modulation of human corticomotor excitability by somatosensory input. J Physiol. 2002;540:623-633.

西

Sullivan JE, Hedman LD. Sensory dysfunction following stroke: incidence, significance, examination, and intervention. Top Stroke Rehabil. 2008;5:200-217.

Yakutiel M. Re-education of the Hand After Stroke. London, UK: Whirr; 2000. Google Scholar

Cordo P, Lutsep H, Cordo L, Wrigth G, Cacciatore T, Skoss R. Assisted Movement With Enhanced Sensation (AMES): coupling motor and sensory to remediate motor deficits in chronic stroke patients. Neurorehabil Neural Repair. 2009;23:67-77. Google Scholar Abstract Shirahashi I, Matsumoto S, Shimodozono M, Etoh S, Kawahira K. Functional vibratory stimulation on the hand facilitates voluntary movements of a hemiplegic upper limb in a patient with stroke. Int J Rehabil Res. 2007;30:227-230. Google Scholar Medline 